\title{
Usefulness of Hemoglobin A1c to Predict Outcome After Cardiac Resynchronization Therapy in Patients With Diabetes Mellitus and Heart Failure
}

\section{Citation}

Shah, Ravi V., Robert K. Altman, Mi Young Park, Jodi Zilinski, Jordan Leyton-Mange, Mary Orencole, Michael H. Picard, et al. 2012. "Usefulness of Hemoglobin A1c to Predict Outcome After Cardiac Resynchronization Therapy in Patients With Diabetes Mellitus and Heart Failure." The American Journal of Cardiology 110 (5) (September): 683-688. doi:10.1016/ j.amjcard.2012.04.056. http://dx.doi.org/10.1016/j.amjcard.2012.04.056.

\section{Published Version}

doi:10.1016/j.amjcard.2012.04.056

\section{Permanent link}

http://nrs.harvard.edu/urn-3:HUL.InstRepos:29048908

\section{Terms of Use}

This article was downloaded from Harvard University's DASH repository, and is made available under the terms and conditions applicable to Other Posted Material, as set forth at http:// nrs.harvard.edu/urn-3:HUL.InstRepos:dash.current.terms-of-use\#LAA

\section{Share Your Story}

The Harvard community has made this article openly available. Please share how this access benefits you. Submit a story. 


\title{
Usefulness of Hemoglobin $A_{1 c}$ to Predict Outcome After Cardiac Resynchronization Therapy in Patients With Diabetes Mellitus and Heart Failure
}

Ravi V. Shah, MD ${ }^{a}, \dagger$, Robert K. Altman, MD $^{b, \dagger}$, Mi Young Park, MD, PhD ${ }^{c}$, Jodi Zilinski, MDa, Jordan Leyton-Mange, MD ${ }^{a}$, Mary Orencole, NP ${ }^{b}$, Michael H. Picard, MD ${ }^{c}$, Conor D. Barrett, MD $^{\mathrm{b}}$, E. Kevin Heist, MD, PhD ${ }^{\mathrm{b}}$, Gaurav Upadhyay, MD $^{\mathrm{b}}$, Ranendra Das, PhD $^{\mathrm{d}}$, Jagmeet $\mathbf{P}$. Singh, MD, DPhil ${ }^{b}$, and Saumya Das, MD, PhDe, ${ }^{*}$

${ }^{a}$ Cardiology Division, Massachusetts General Hospital, Harvard Medical School, Boston, Massachusetts ${ }^{b}$ Cardiac Arrhythmia Unit, Massachusetts General Hospital, Harvard Medical School, Boston, Massachusetts ${ }^{c}$ Echocardiography Laboratory of the Department of Medicine, Massachusetts General Hospital, Harvard Medical School, Boston, Massachusetts dDepartment of Anthropology, Johns Hopkins University, Baltimore, Maryland eDepartment of Cardiology and Medicine, Beth Israel Deaconess Medical Center, Boston, Massachusetts

\begin{abstract}
Patients with diabetes and heart failure (HF) have worse clinical outcomes compared to patients with HF without diabetes after cardiac resynchronization therapy (CRT). Patients with HF and diabetes represent a growing population at high risk for cardiovascular events and are increasingly treated with CRT. Although patients with diabetes and HF appear to benefit from CRT, their clinical outcomes are worse than those of patients without diabetes after CRT. The aim of this study was to identify clinical predictors that explain the differential hazard in patients with diabetes. We studied 442 patients (169 with diabetes) with systolic HF referred to the Massachusetts General Hospital CRT clinic from 2003 to 2010 to identify predictors of outcomes after CRT in patients with HF and diabetes. Patients with diabetes were more likely to have ischemic causes of HF than those without diabetes, but there was no difference in the left ventricular ejection fraction or HF classification at implantation. Patients with diabetes had poorer event-free survival (death or HF hospitalization) compared to those without diabetes (log-rank $p=$ 0.04). The presence of diabetes was the most important independent predictor of differential outcomes in the entire population (hazard ratio 1.65, 95\% confidence interval 1.10 to 2.51). Patients with diabetes receiving insulin therapy had poorer survival, whereas those not receiving insulin therapy had similar survival to patients without diabetes. Patients with peri-implantation glycosylated hemoglobin $>7 \%$ had worse outcomes, whereas patients with glycosylated hemoglobin $\leq 7 \%$ had improved survival (hazard ratio $0.36,95 \%$ confidence interval 0.15 to 0.86 ) equivalent to that of patients without diabetes. In conclusion, although the presence of diabetes, independent of other variables, increases the hazard of worse outcomes after CRT, there is additional risk conferred by insulin use and suboptimal peri-implantation glycemic control.
\end{abstract}

(C) 2012 Elsevier Inc. All rights reserved.

*Corresponding author: Tel: 617-735-4241; fax: 617-667-7620. sdas@bidmc.harvard.edu (S. Das).

$\dagger$ Drs. Shah and Altman contributed equally to this article.

Supplementary data

Supplementary data associated with this article can be found, in the online version, at http://dx.doi.org/10.1016/j.amjcard.2012.04.056. 
In patients with advanced systolic heart failure (HF) and wide QRS complexes, cardiac resynchronization therapy (CRT) leads to improvements in survival and functional status and reductions in subsequent HF hospitalizations. ${ }^{1,2}$ Given the growing prevalence of diabetes mellitus in patients with newly diagnosed $\mathrm{HF},{ }^{3}$ assessing the impact of diabetes on response to CRT is critical. Although recent studies have suggest that patients with and those without diabetes derive similar relative benefits from CRT therapy with defibrillation compared to implantable cardioverterdefibrillator therapy alone, ${ }^{4-7}$ patients with diabetes still experience poorer clinical outcomes compared to those without diabetes after CRT. ${ }^{7}$ Therefore, it is critical to identify clinical risk factors that may explain the differential outcomes between patients with and those without diabetes. We studied patients referred for CRT at the Massachusetts General Hospital (MGH) stratified by diabetic status to identify predictors of response to CRT in patients with diabetes compared to those without diabetes. Finally, to address the impact of hyperglycemia and insulin therapy ${ }^{6}$ in patients with diabetes, we studied the effect of preimplantation insulin use and glycosylated hemoglobin $\left(\mathrm{HbA}_{1 \mathrm{c}}\right)$ on clinical outcomes after CRT.

\section{Methods}

We studied 442 patients ( 169 with diabetes) who underwent CRT device implantation at MGH from February 2003 and February 2010. Patients who were followed in the MGH multidisciplinary CRT clinic $(n=304$ [69\%]), established in November 2005, had prospective collection of demographic, clinical, and biochemical data. The remaining 138 patients (31\%) had data collected retrospectively. CRT device implantation was performed at MGH using a standard transvenous approach or an epicardial approach, when clinically indicated.

Diabetic status was determined by any clinical diagnosis of diabetes in the medical record (medical notes or discharge summaries) before CRT device implantation. Patients with positive stress test results or $\geq 1$ epicardial coronary artery stenosis $>50 \%$ by review of medical records were adjudicated as having coronary artery disease. The cause of cardiomyopathy was adjudicated by a cardiologist in our registry and confirmed by a second independent cardiologist. In patients with diabetes, $\mathrm{HbA}_{1 \mathrm{c}}$ (obtained on clinical indications) was included if it was drawn from 100 days before to 30 days after CRT device implantation. Of the 169 eligible patients with diabetes (38\% of the overall population), 83 patients (49\%) had peri-implantation $\mathrm{HbA}_{1 \mathrm{c}}$ values assessed.

Preimplantation and 6-month postimplantation transthoracic echocardiography was performed as a part of the clinical evaluation of these patients (Table 1). The left ventricular ejection fraction (LVEF) was calculated using the MGH single-dimension method, with method of disks used at the discretion of the interpreter. For patients with atrial fibrillation, 5 beats were averaged. Response to CRT was defined as an absolute increase in the LVEF $>5 \%$ or a relative decrease in left ventricular end-systolic diameter $>10 \%$. Of the overall population, 411 patients (157 with diabetes [93\%], 254 without diabetes [93\%], overall 93\%) underwent clinically indicated preimplantation echocardiographic studies.

Postimplantation echocardiograms were available in 283 patients (176 without diabetes [64\%], 107 with diabetes [63\%], overall 64\%).

The primary end point of this study was all-cause mortality or HF hospitalization, whichever came first, $<2$ years after CRT device implantation, with postimplantation 30-day blanking period for events. Patients with events or loss to follow-up within the 30-day blanking period ( 2 patients of the overall cohort) were excluded from analysis. Medical records from MGH (from our multidisciplinary CRT clinic and the MGH electronic medical record) and 
Social Security Death Index were reviewed for data collection and adjudication of vital status at 2 years.

Clinical and echocardiographic characteristics (at baseline and follow-up) were compared between patients with and without diabetes using Student's $t$ tests (for continuous variables) and Fisher's exact tests (for categorical covariates), with $\mathrm{p}$ values $<0.05$ considered significant. Kaplan-Meier survival analysis was used to compare event-free survival at 2 years stratified by diabetic status (log-rank $\mathrm{p}$ values $<0.05$ were considered significant), with a 30-day initial blanking period to limit the effect of early postprocedural adverse events. Cox proportional-hazards models including diabetic status and preimplantation covariates known to affect outcome after CRT (e.g., age, gender, serum creatinine, QRS duration, LVEF, New York Heart Association [NYHA] functional class, ischemic cause of HF, and insulin use in patients with diabetes) were used to identify predictors of event-free survival at 2 years ( $p$ values $<0.05$ were considered significant). The best Cox model was selected by the criterion of statistical significance of included variables and the fitted regression equation. The link test was performed to confirm that these explanatory variables correctly specified our regression model, and the proportional-hazard assumption was tested using an estat proportional-hazard test based on a scaled Schoenfeld residual.

Given that $7 \%$ was the median value for eligible peri-implantation $\mathrm{HbA}_{1 \mathrm{c}}$ in the 83 patients with available values (and that $7 \%$ is the currently accepted treatment target in diabetes), we analyzed baseline clinical and echocardiographic characteristics, survival, and Cox models in these 83 patients with diabetes stratified by $\mathrm{HbA}_{1 \mathrm{c}}>7 \%$ and $\$ 7 \%$ using methods specified earlier. Analyses were performed using Stata version 11 (StataCorp LP, College Station, Texas).

\section{Results}

The results of baseline clinical, biochemical, and echocardiographic characteristics are listed in Table 1. Compared to the patients without diabetes, those with diabetes were more likely to have ischemic causes of HF ( $\mathrm{p}=0.001$ ), hypertension ( $\mathrm{p}<0.0001$ ), and previous coronary artery bypass graft surgery $(\mathrm{p}<0.0001)$. Baseline echocardiographic indexes (Table 1), QRS durations, types of interventricular conduction delay, serum creatinine values, and NYHA classes on study entry were similar in the 2 groups. At follow-up, patients with diabetes had slightly lower LVEFs $(\mathrm{p}=0.002)$ than those without diabetes but no significant difference in left ventricular dimensions (Table 1). There was also no significant difference in changes in left ventricular dimension or echocardiographic responsiveness (defined by change in LVEF $>5 \%$ or LV endsystolic diameter $<10 \%$ ) between patients with and those without diabetes over the study period (Table 2).

At median follow-up, 338 patients (76\%) had clinical follow up data at 2 years (either an event occurred within 2 years or they survived event free for 2 years). The remaining 104 patients ( 30 with and 74 without diabetes) were either lost to follow-up or were not yet 2 years out from the implantation date at the time of analysis (censored at 2 years). The mean follow-up time was $413 \pm 197$ days $(440 \pm 193$ days in patients with diabetes vs $402 \pm 198$ days in those without, $p=0.36$ ). In the entire cohort, 168 patients met $\geq 1$ end point (HF hospitalization or death) after the 30-day blanking period within 2 years (76 with diabetes and 92 without), with a total of 89 deaths (42 in patients with diabetes and 57 in those without).

Echocardiographic response to CRT (as defined previously) predicted outcomes at 2 years in patients with diabetes (hazard ratio [HR] 0.55, p <0.05) and in those without diabetes (HR $0.41, \mathrm{p}<0.05$ ) (Table 3 ) in an unadjusted Cox model. However, patients with diabetes had 
poorer survival free of death or HF hospitalization compared to those without diabetes (logrank $\mathrm{p}=0.04$; Figure 1). In an unadjusted Cox model in patients without diabetes, only serum creatinine (HR 1.39, $\mathrm{p}<0.05$ ), preimplantation baseline NYHA class (HR 2.80, p $<0.05$ ), and echocardiographic response predicted outcomes (Table 3).

In patients with diabetes, creatinine (HR 2.05, $\mathrm{p}<0.05$ ), baseline NYHA class (HR 2.29, $\mathrm{p}$ $<0.05$ ), insulin use (HR 1.84, $\mathrm{p}<0.05$ ), and echocardiographic response predicted outcomes (Table 3). In multivariate Cox models $(n=285)$, serum creatinine (HR 1.46, $\mathrm{p}<0.05$ ), baseline NYHA class (HR 2.03, p <0.05), the LVEF (HR 0.97, p <0.05), $\beta$-blocker use at implantation (HR 0.44, p <0.05), and the presence of diabetes (HR 1.65, p <0.05) were significant predictors of outcomes at 2 years (Table 4). Stratified for the presence of diabetes, baseline NYHA class, the baseline LVEF, creatinine, and $\beta$-blocker use were statistically equivalent hazards in patients with and those without diabetes and hence did not explain the differential outcomes between the 2 groups. Diabetes added $65 \%$ higher risk in subjects with equivalent baseline NYHA functional class, LVEFs, serum creatinine values, and $\beta$-blocker use, shown by a Cox model stratified by the presence of diabetes (Supplementary Figure 1). Thus, the presence of diabetes (independent of other comorbidities including ischemia) was the most important hazard in predicting differential outcomes between patients with and those without diabetes. Ischemic cause of HF, QRS duration $>150 \mathrm{~ms}$, age, and female gender were not significant predictors of outcome in any of the proportional-hazards regression models. Furthermore, patients with diabetes with ischemic causes of HF did not have statistically different event-free survival at 2 years compared to patients with diabetes with nonischemic HF (Supplementary Figure 2).

Given prior work suggesting that the use of insulin therapy may be responsible for the adverse prognosis of HF in patients with diabetes after CRT, ${ }^{6}$ we used Kaplan-Meier analysis to assess event-free survival at 2 years in patients without diabetes, those with diabetes receiving insulin therapy, and those with diabetes not receiving insulin therapy. Event-free survival at 2 years in patients without diabetes was identical to that in patients with diabetes not receiving insulin therapy $(\log -\operatorname{rank} p=0.62)$, and the 2 groups fared better than patients with diabetes receiving insulin therapy (log-rank $p=0.002$ for equality of survivor function among all 3 groups; Figure 2). However, in a multivariate regression model using insulin as an additional explanatory variable, insulin use did not reach significance as a predictor of outcomes in patients with diabetes, although there was a trend noted (HR 1.76, $\mathrm{p}=0.08)$.

Of 169 patients with diabetes, 83 had peri-implantation $\mathrm{HbA}_{1 \mathrm{c}}$ values available. There was no difference in any baseline clinical, biochemical, or echocardiographic variable between patients with diabetes who did and did not have peri-implantation $\mathrm{HbA}_{1 \mathrm{c}}$ values available (Supplementary Table 1). In addition, there was no difference in baseline characteristics between patients with diabetes with $\mathrm{HbA}_{1 \mathrm{c}}>7 \%$ and $\$ 7 \%$ (the median value in our study), except for insulin use (60\% vs $21 \%, \mathrm{p}=0.0003)$ and male gender ( $90 \%$ vs $67 \%, \mathrm{p}=0.02)$, more prevalent in patients with $\mathrm{HbA}_{1 \mathrm{c}}>7 \%$.

A Kaplan-Meier curve depicting unadjusted event-free survival in patients with diabetes with $\mathrm{HbA}_{1 \mathrm{c}}>7 \%$ versus $\mathrm{HbA}_{1 \mathrm{c}} \leq 7 \%$ is shown in Figure 2. Patients with diabetes with periimplantation $\mathrm{HbA}_{1 \mathrm{c}} \leq 7 \%$ had higher event-free survival compared to those with higher $\mathrm{HbA}_{1 \mathrm{c}}$ values (log-rank $\mathrm{p}=0.002$; Figure 3 ). Again, this difference appeared within the first 90 days of follow-up, suggesting an interaction between CRT therapy and peri-implantation $\mathrm{HbA}_{1 \mathrm{c}}$. In 83 patients with available $\mathrm{HbA}_{1 \mathrm{c}}$ values and 34 noted events, $\mathrm{HbA}_{1 \mathrm{c}} \leq 7 \%$ was protective (univariate HR $0.39, \mathrm{p}<0.05$ ). $\mathrm{HbA}_{1 \mathrm{c}} \leq 7 \%$ (HR 0.36, $\mathrm{p}<0.05$ ) remained significant when adjusted for baseline NYHA functional class, the baseline LVEF, and $\beta$ blocker use at implantation in a Cox multivariate regression with 64 sample observations 
(Table 5). Although the smaller sample size reduced the power of statistical testing, the pattern of results from several Cox regressions demonstrated the stability of the results. Of note, the addition of insulin use as an additional explanatory variable to this multivariate model led to deterioration in the significance of the overall fit of the Cox regression model, because of negative collinearity between $\mathrm{HbA}_{1 \mathrm{c}} \leq 7 \%$ and insulin use (tetrachoric correlation coefficient $=-0.59$ ). Similar to the survival results observed with stratification by insulin therapy (Figure 2), there was no difference in eventfree survival at 2 years between patients with diabetes with $\mathrm{HbA}_{1 \mathrm{c}} \leq 7 \%$ and patients without diabetes (Figure 3).

\section{Discussion}

Our study of 442 patients ( 169 with diabetes) showed that improvement in the LVEF predicted improved clinical outcomes in patients with and those without diabetes, in agreement with recent results suggesting that CRT with defibrillation improves outcomes in patients with diabetes beyond an implantable cardioverter-defibrillator. ${ }^{6,7}$ However, in concert with previous studies that showed increased risk for mortality and HF hospitalization in patients with diabetes and those without, ${ }^{8,9}$ the patients with diabetes in our cohort had significantly poorer outcomes after CRT. Serum creatinine, baseline NYHA functional class, the baseline LVEF, $\beta$-blocker use, and the presence of diabetes were significant independent predictors of outcomes in the entire cohort. When stratified by the presence of diabetes, the first 4 variables were statistically equivalent hazards in the diabetic and nondiabetic subgroups and could not explain the differential outcomes between the 2 groups. However, the presence of diabetes added a hazard of $65 \%$ higher risk independent of these other variables, suggesting a unique effect of diabetes on outcomes independent of clinical risk.

Importantly, our findings suggest that insulin use and glycemic control may affect long-term outcomes in patients with diabetes with HF. Patients with diabetes not receiving insulin therapy had a similar overall event rate compared to those without diabetes, whereas patients with diabetes receiving insulin therapy had markedly poorer long-term event-free survival. Moreover, in a subgroup of patients with $\mathrm{HbA}_{1 \mathrm{c}}$ values available, we discovered that patients with guideline-recommended glycemic control $\left(\mathrm{HbA}_{1 \mathrm{c}} \leq 7 \%\right)$ had significantly better event-free survival at 2 years. Furthermore, long-term event-free survival was equivalent between patients with diabetes with $\mathrm{HbA}_{1 \mathrm{c}} \leq 7 \%$ and those without diabetes. Although it is well known that patients with diabetes fare more poorly than those without diabetes with HF, the markedly worse prognosis in patients receiving insulin or with poor peri-implantation glycemic control suggests the possibility that more advanced diabetes (as signaled by requirement for insulin therapy or a higher $\mathrm{HbA}_{1 \mathrm{c}}$ value) before CRT device implantation may be an important determinant of post-CRT outcomes.

The impact of peri-implantation glycemic control on post-CRT outcomes is a novel addition to the current published work on CRT in diabetic HF. Martin et $\mathrm{al}^{7}$ reported on 552 patients with diabetes from the Multicenter Automated Defibrillator Implantation Trial With Cardiac Resynchronization Therapy (MADIT-CRT), demonstrating that although patients with diabetes do derive benefit from CRT compared to implantable cardioverter-defibrillator therapy alone, they have poorer event-free survival compared to patients without diabetes a mean of 2.4 years after CRT device implantation. However, this study enrolled patients with milder $\mathrm{HF}$ and did not describe insulin use, $\mathrm{HbA}_{1 \mathrm{c}}$, or their effects on outcome. In another large, recent study of 447 patients referred for CRT for clinical indications, patients with diabetes receiving insulin therapy had poorer survival compared to patients without diabetes out to 5 years after CRT, ${ }^{10}$ attended by a poorer improvement in the LVEF after CRT. ${ }^{10}$ Finally, in a substudy of 207 patients with diabetes in the Cardiac Resynchronization in Heart Failure (CARE-HF) trial, although CRT was found to reduce all-cause mortality to a 
similar degree in patients with and those without diabetes, ${ }^{6}$ the patients with diabetes receiving insulin therapy had poorer long-term survival compared to those receiving noninsulin-based therapies, ${ }^{6}$ similar to our results.

Although 1 interpretation of our results is that patients with diabetes with better glycemic control may represent a healthier subgroup with milder HF that does better after any kind of therapy, the early post-CRT clinical response raises the intriguing possibility that periimplantation glycemic control (to guideline-recommended targets) may lead to more favorable long-term clinical outcomes after CRT device implantation in patients with diabetes. Formal testing of this hypothesis in a randomized-controlled prospective trial is warranted in the future.

Although our study was limited by the absence of full echocardiographic and HbA1c data for all diabetic patients (thereby underpowering some of the analyses), our results agree with several published reports on CRT in diabetic HF and are plausible given the current understanding of diabetic HF. In addition, adjudication of diabetic status was performed by chart review of records from physician visits (not by formal glucose tolerance testing), and $\mathrm{HbA}_{1 \mathrm{c}}$ values were obtained routinely only for clinical indications. However, the patients referred for $\mathrm{HbA}_{1 \mathrm{c}}$ testing were not systematically different compared to patients without $\mathrm{HbA}_{1 \mathrm{c}}$ values (no referral bias; Supplementary Table 1).

\section{Supplementary Material}

Refer to Web version on PubMed Central for supplementary material.

\section{Acknowledgments}

Dr. Shah is supported by Post-Doctoral Fellowship Award 11POST000002 from the American Heart Association, Dallas, Texas, and training grant U01-HL084877 from the Heart Failure NIH-NHLBI Clinical Research Network, Bethesda, Maryland. Dr. Upadhyay is supported by a Max Schaldach Fellowship in Cardiac Pacing and Electrophysiology from the Heart Rhythm Society, Washington, District of Columbia. Dr. Das is supported by grant KO8HL089319 from the National Institutes of Health, Bethesda, Maryland.

\section{References}

1. Bristow M, Saxon L, Boehmer J, Krueger S, Kass D, DeMarco T, Carson P, DiCarlo L, DeMets D, White B, DeVries D, Feldman A. Cardiac resynchronization therapy with or without an implantable defibrillator in advanced chronic heart failure (COMPANION). N Engl J Med. 2004; 350:2140 2150. [PubMed: 15152059]

2. Cleland J, Daubert J, Erdmann E, Freemantle N, Gras D, Kappenberger L, Tavazzi L. The effect of cardiac resynchronization on morbidity and mortality in heart failure. N Engl J Med. 2005; 352:1539-1549. [PubMed: 15753115]

3. From A, Leibson C, Bursi F, Redfield M, Weston S, Jacobsen S, Rodeheffer R, Roger V. Diabetes in heart failure: prevalence and impact on outcome in the population. Am J Med. 2006; 119:591599. [PubMed: 16828631]

4. Fantoni C, Regoli F, Ghanem A, Raffa S, Klersy C, Sorgente A, Faletra F, Baravelli M, Inglese L, Salerno-Uriarte J, Klein H, Moccetti T, Auricchio A. Long-term outcome in diabetic heart failure patients treated with cardiac resynchronization therapy. Eur J Heart Fail. 2008; 10:298-307. [PubMed: 18296111]

5. Ghali J, Boehmer J, Feldman A, Saxon L, DeMarco T, Carson P, Yong P, Galle E, Leigh J, Ecklund F, Bristow M. Influence of diabetes on cardiac resynchronization therapy with or without defibrillator in patients with advanced heart failure. J Card Fail. 2007; 13:769-773. [PubMed: 17996827] 
6. Hoppe U, Marjianowski M, Freemantle N, Erdmann E, Cleland J. Effect of cardiac resynchronization on morbidity and mortality of diabetic patients with severe heart failure. Diabetes Care. 2007; 30:722-724. [PubMed: 17327349]

7. Martin D, McNitt S, Nesto R, Rutter M, Moss A. Cardiac resynchronization therapy reduces the risk of cardiac events in patients with diabetes enrolled in the Multicenter Automatic Defibrillator Implantation Trial With Cardiac Resynchronization Therapy (MADIT-CRT). Circ Heart Fail. 2011; 4:332-338. [PubMed: 21350054]

8. Shindler D, Kostis J, Yusuf S, Quinones M, Pitt B, Stewart D, Pinkett T, Wilson A. Diabetes mellitus: a predictor of morbidity and mortality in the Studies of Left Ventricular Dysfunction (SOLVD) trials and registry. Am J Cardiol. 1996; 77:1017-1020. [PubMed: 8644628]

9. Pocock S, Wang D, Pfeffer M, Yusuf S, McMurray J, Swedberg K, Ostergren J, Michelson E, Pieper K, Granger C. Predictors of mortality and morbidity in patients with chronic heart failure. Eur Heart J. 2006; 27:65-75. [PubMed: 16219658]

10. Mangiavacchi M, Gasparini M, Genovese S, Pini D, Klersy C, Bragato R, Andreuzzi B, Municino A, Regoli F, Galimberti P, Ceriotti C, Gronda E. Insulin-treated type 2 diabetes is associated with a decreased survival in heart failure patients after cardiac resynchronization therapy. Pacing Clin Electrophysiol. 2008; 31:1425-1432. [PubMed: 18950300] 


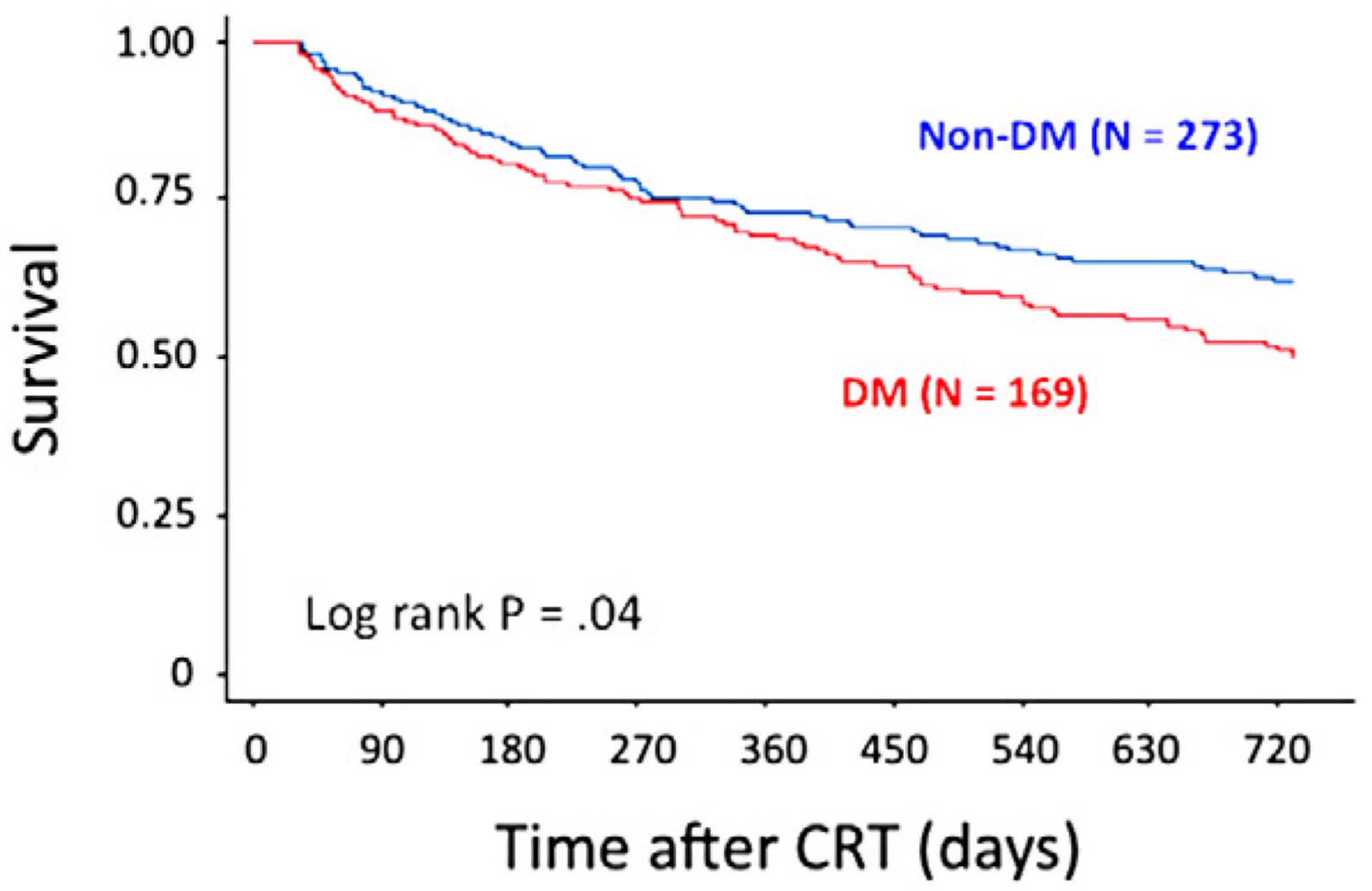

Number at risk

$\begin{array}{llllllllll}\text { Non-DM: } & 273 & 242 & 220 & 195 & 170 & 151 & 137 & 121 & 105\end{array}$ $\begin{array}{llllllllll}\text { DM: } & 169 & 147 & 133 & 122 & 108 & 96 & 84 & 73 & 62\end{array}$

Figure 1.

Kaplan-Meier event-free survival curves by diabetic status. Numbers at risk for the 2 cohorts are shown below the graph. $\mathrm{DM}=$ diabetes mellitus. 


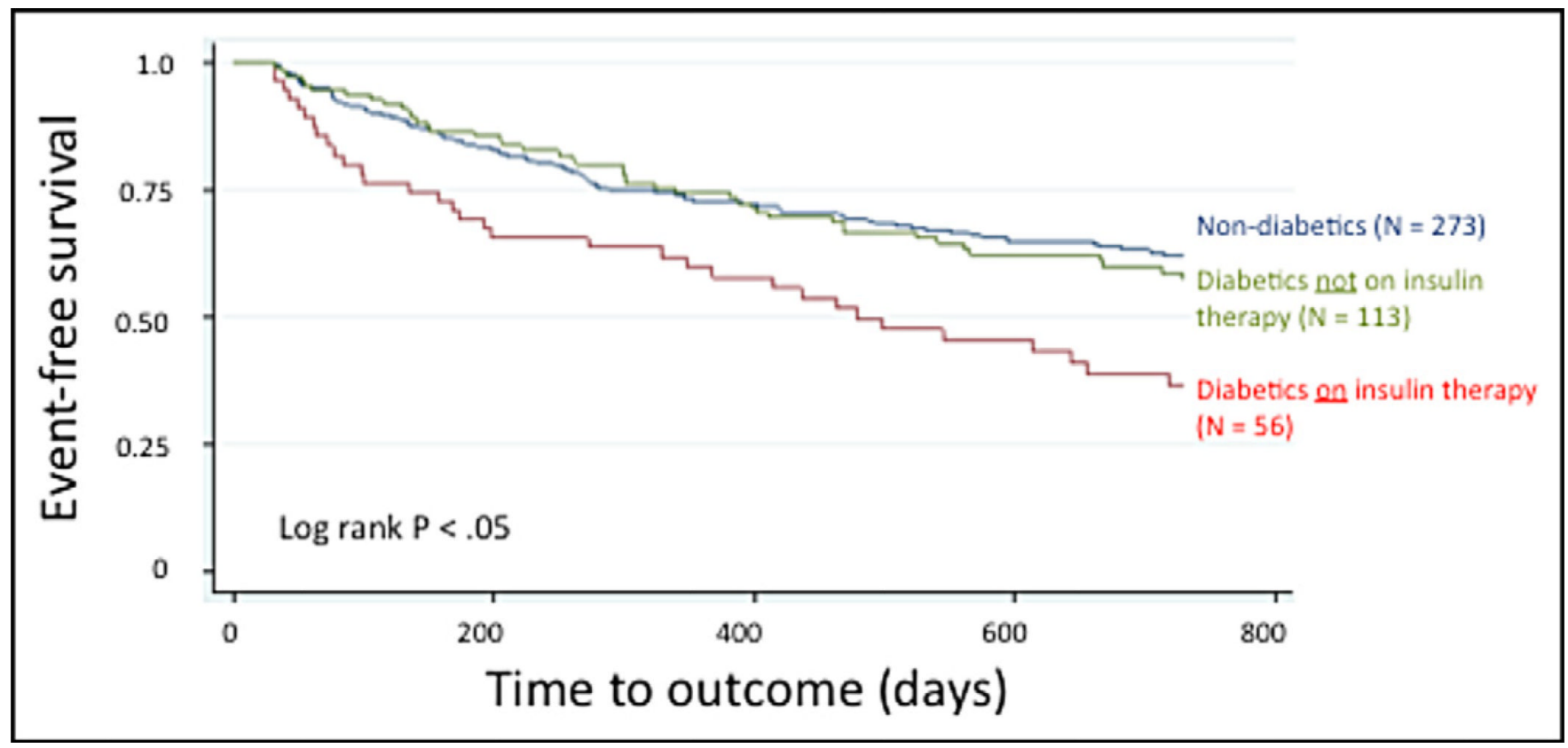

Figure 2.

Kaplan-Meier event-free survival curves of patients without diabetes, patients with diabetes receiving insulin therapy, and patients with diabetes not receiving insulin therapy. 


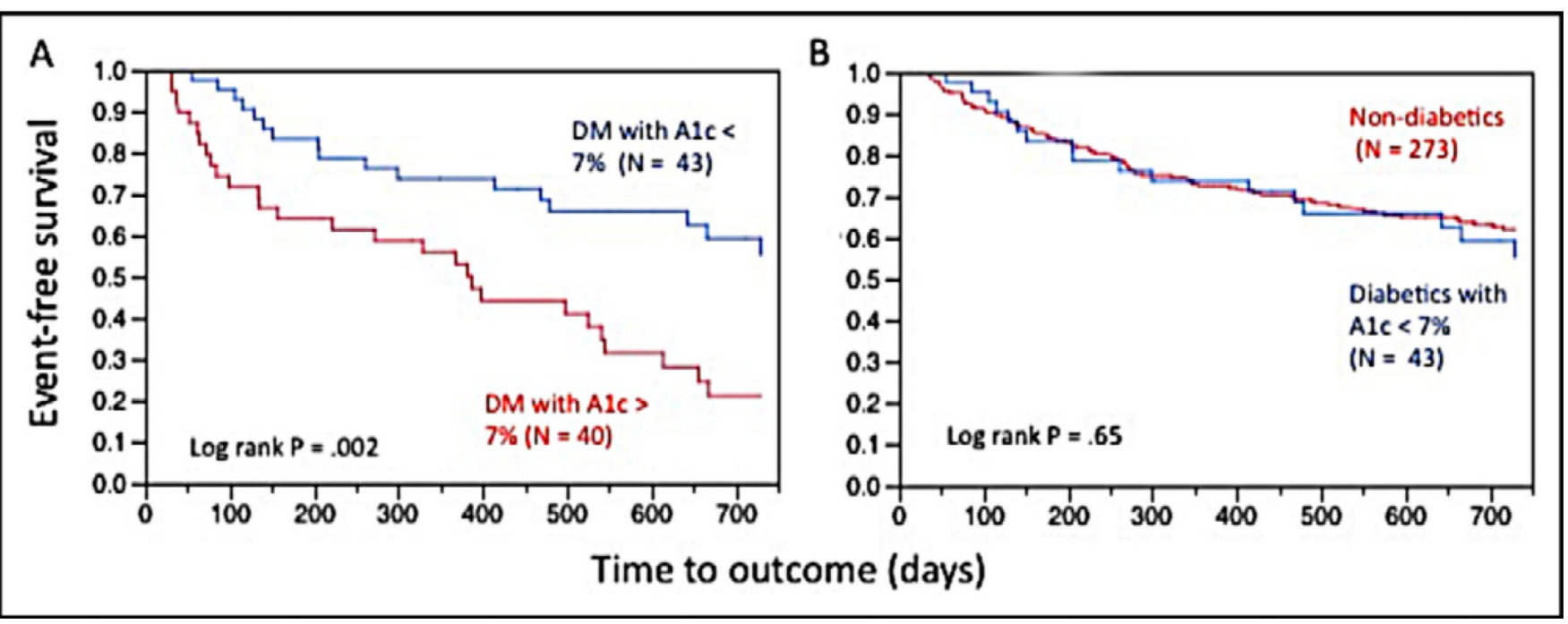

Figure 3.

Kaplan-Meier event-free survival curves of $(A)$ patients with diabetes with $\mathrm{HbA}_{1 \mathrm{c}} \leq 7 \%$ versus $\mathrm{HbA}_{1 \mathrm{c}}>7 \%$ and $(B)$ patients with diabetes with $\mathrm{HbA}_{1 \mathrm{c}} \leq 7 \%$ versus patients without diabetes. $\mathrm{DM}=$ diabetes mellitus. 
Table 1

Baseline clinical characteristics of the study population

\begin{tabular}{|c|c|c|c|}
\hline \multirow[t]{2}{*}{ Characteristic } & \multicolumn{2}{|c|}{ Diabetes Mellitus } & \multirow[t]{2}{*}{ p Value } \\
\hline & $\begin{array}{l}\text { Yes } \\
(n=169)\end{array}$ & $\begin{array}{l}\text { No } \\
(n=273)\end{array}$ & \\
\hline Age (years) & $69 \pm 10$ & $68 \pm 14$ & 0.35 \\
\hline Men & $139(82 \%)$ & $221(81 \%)$ & 0.80 \\
\hline Ischemic cardiomyopathy & $114(67 \%)$ & $140(51 \%)$ & 0.001 \\
\hline Transvenous CRT placement & $154(91 \%)$ & $256(94 \%)$ & 0.35 \\
\hline Hypertension & $143(85 \%)$ & $180(66 \%)$ & $<0.0001$ \\
\hline Coronary artery disease & $132(78 \%)$ & $161(59 \%)$ & $<0.0001$ \\
\hline Permanent atrial fibrillation & $63(37 \%)$ & $91(33 \%)$ & 0.41 \\
\hline Previous coronary artery bypass grafting & $92(54 \%)$ & $89(33 \%)$ & $<0.0001$ \\
\hline Previous percutaneous coronary intervention & $48(28 \%)$ & $68(25 \%)$ & 0.44 \\
\hline \multicolumn{4}{|l|}{ Medications on presentation } \\
\hline$\beta$ blockers & $148(88 \%)$ & $239(88 \%)$ & 1.00 \\
\hline Any diuretic & $151(89 \%)$ & $233(85 \%)$ & 0.25 \\
\hline Digoxin & $73(43 \%)$ & $120(44 \%)$ & 0.92 \\
\hline Angiotensin-converting enzyme inhibitors or angiotensin receptor blockers & $134(79 \%)$ & $225(82 \%)$ & 0.45 \\
\hline Aldosterone antagonists & $60(36 \%)$ & $84(31 \%)$ & 0.35 \\
\hline \multicolumn{4}{|l|}{ Baseline echocardiography } \\
\hline Time before implantation (days) & $66 \pm 107$ & $59 \pm 93$ & 0.48 \\
\hline $\operatorname{LVEF}(\%)$ & $23 \pm 7$ & $23 \pm 7$ & 0.77 \\
\hline LV end-diastolic diameter $(\mathrm{mm})$ & $62 \pm 8$ & $63 \pm 9$ & 0.25 \\
\hline LV end-systolic diameter (mm) & $54 \pm 9$ & $55 \pm 10$ & 0.58 \\
\hline \multicolumn{4}{|l|}{ Follow-up echocardiography } \\
\hline Time after implantation (days) & $215 \pm 61$ & $206 \pm 47$ & 0.24 \\
\hline $\operatorname{LVEF}(\%)$ & $28 \pm 11$ & $33 \pm 12$ & 0.002 \\
\hline LV end-diastolic diameter (mm) & $59 \pm 8$ & $60 \pm 11$ & 0.98 \\
\hline LV end-systolic diameter (mm) & $51 \pm 9$ & $50 \pm 12$ & 0.68 \\
\hline QRS duration at implantation (ms) & $159 \pm 28$ & $161 \pm 29$ & 0.39 \\
\hline QRS duration > $150 \mathrm{~ms}$ & $102(63 \%)$ & $153(61 \%)$ & 0.76 \\
\hline Serum creatinine (mg/dl) & $1.6 \pm 0.6$ & $1.5 \pm 0.7$ & 0.19 \\
\hline NYHA class at presentation & $3.1 \pm 0.4$ & $3.0 \pm 0.4$ & 0.17 \\
\hline Class IV at presentation & $15(12 \%)$ & $22(10 \%)$ & 0.72 \\
\hline NYHA class at 6 mo & $2.5 \pm 0.8$ & $2.2 \pm 0.8$ & 0.002 \\
\hline Class IV at 6 mo & $10(9 \%)$ & $8(5 \%)$ & 0.14 \\
\hline
\end{tabular}

Data are expressed as mean $\pm \mathrm{SD}$ or as number (percentage).

$\mathrm{LV}=$ left ventricular. 
Table 2

Clinical and echocardiographic response to cardiac resynchronization therapy

\begin{tabular}{lccc}
\hline Responsiveness & \multicolumn{2}{c}{ Diabetes Mellitus } & \multirow{2}{*}{ p Value } \\
\cline { 2 - 3 } & \multicolumn{2}{c}{ Yes } & No \\
\hline Change in LVEF at follow-up (\%) & $5.5 \pm 10$ & $8.9 \pm 11$ & 0.01 \\
Change in LV end-diastolic diameter at follow-up (mm) & $0.05 \pm 0.1$ & $0.06 \pm 0.1$ & 0.43 \\
Change in LV end-systolic diameter at follow-up (mm) & $0.06 \pm 0.12$ & $0.08 \pm 0.14$ & 0.42 \\
Change in NYHA class & $-0.6 \pm 0.9$ & $-0.8 \pm 0.8$ & 0.06 \\
Responder, LVEF increase >5\% & $54(52 \%)$ & $103(62 \%)$ & 0.16 \\
Responder, LV end-diastolic diameter decrease $>10 \%$ & $25(26 \%)$ & $55(34 \%)$ & 0.21 \\
Responder, LV end-systolic diameter decrease $>10 \%$ & $36(41 \%)$ & $64(43 \%)$ & 0.79 \\
Responder by LV end-systolic diameter or LVEF & $60(58 \%)$ & $114(68 \%)$ & 0.12 \\
\hline
\end{tabular}

Data are expressed as mean \pm SD or as number (percentage).

$\mathrm{LV}=$ left ventricular. 


\section{Table 3}

Unadjusted (univariate) Cox proportional-hazards model for event-free survival at 2 years in patients without and with diabetes

\begin{tabular}{|c|c|c|c|c|}
\hline \multirow[t]{3}{*}{ Covariate } & \multicolumn{4}{|c|}{ Diabetes Mellitus } \\
\hline & \multicolumn{2}{|r|}{ No } & \multicolumn{2}{|r|}{ Yes } \\
\hline & HR & $95 \% \mathrm{CI}$ & HR & $95 \% \mathrm{CI}$ \\
\hline Age at implantation & 1.00 & $0.99-1.02$ & 1.01 & $0.98-1.03$ \\
\hline Female gender & 0.51 & $0.27-0.96$ & 0.76 & $0.40-1.44$ \\
\hline Serum creatinine (per unit mg/dl) & 1.39 & $1.14-1.69^{*}$ & 2.05 & $1.54-2.73$ * \\
\hline QRS duration $>150 \mathrm{~ms}$ & 0.66 & $0.43-1.01$ & 0.81 & $0.51-1.29$ \\
\hline Baseline NYHA class & 2.80 & $1.55-5.05^{*}$ & 2.29 & $1.12-4.66^{*}$ \\
\hline LVEF & 0.97 & $0.97-1.00$ & 0.99 & $0.96-1.03$ \\
\hline Ischemic cause of HF & 1.45 & $0.95-2.19$ & 1.29 & $0.78-2.13$ \\
\hline$\beta$-blocker use at implantation & 0.67 & $0.39-1.16$ & 0.54 & $0.30-0.99$ \\
\hline Echocardiographic responder & 0.41 & $0.23-0.73^{*}$ & 0.55 & $0.31-0.99^{*}$ \\
\hline Insulin use & NA & NA & 1.84 & $1.17-2.88^{*}$ \\
\hline
\end{tabular}

$\mathrm{CI}=$ confidence interval; $\mathrm{NA}=$ not applicable.

p $<0.05$. 


\section{Table 4}

Adjusted multivariate Cox proportional-hazards model for event-free survival at 2 years in the overall population, including diabetic status $(n=275$ available)

\begin{tabular}{llc}
\hline Covariate & HR & 95\% Confidence Interval \\
\hline Age at implantation & 1.00 & $0.98-1.02$ \\
Female gender & 0.55 & $0.28-1.08$ \\
Serum creatinine & $1.46^{*}$ & $1.18-1.79$ \\
QRS >150 ms & 0.86 & $0.57-1.31$ \\
Baseline NYHA class & $2.03^{*}$ & $1.16-3.54$ \\
LVEF & $0.97^{*}$ & $0.94-1.00$ \\
Ischemic cause of HF & 1.11 & $0.70-1.75$ \\
$\beta$-blocker use at implantation & $0.44^{*}$ & $0.25-0.74$ \\
Presence of diabetes mellitus & $1.65^{*}$ & $1.10-2.51$ \\
\hline
\end{tabular}

* ${ }^{*}<0.05$. 
Table 5

Adjusted multivariate Cox proportional-hazards model for event-free survival at 2 years in patients with diabetes $(n=65)$

\begin{tabular}{lll}
\hline Covariate & \multicolumn{2}{c}{ Patients With Diabetes } \\
\cline { 2 - 3 } & HR & 95\% Confidence Interval \\
\hline Age at implantation & 1.02 & $0.98-1.07$ \\
Female gender & 0.51 & $0.15-1.74$ \\
Serum creatinine $>2 \mathrm{mg} / \mathrm{dl} 1$ & 1.52 & $0.64-3.61$ \\
QRS $>150$ ms & 0.91 & $0.43-1.94$ \\
Baseline NYHA class & $3.31 *$ & $1.11-9.88$ \\
LVEF & $0.92^{*}$ & $0.86-0.99$ \\
Ischemic cause of HF & 0.90 & $0.40-2.06$ \\
$\beta$-blocker use at implantation & $0.23^{*}$ & $0.08-0.70$ \\
HbA ${ }_{1 c} \leq 7 \%$ & $0.36^{*}$ & $0.15-0.86$ \\
\hline
\end{tabular}

* $<<0.05$. 